\title{
Perceived psychological stress among undergraduate students: role of academic factors of a medical college of Kathmandu
}

\author{
Jyoti Badan Tuladhar* \\ Department of Nursing, Kathmandu Medical College Teaching Hospital, Kathmandu, Nepal
}

\begin{abstract}
Introduction: Stress refers to a dynamic interaction between the individual and the environment, which described as external demands (physical or mental) on an individual's physical and psychological well-being. The objective of this study was to assess the perceived psychological stress and perception of academic stress among undergraduate students. Methods: A cross-sectional, questionnaire- based survey was carried out among 853 undergraduate students (medical, dental and nursing) of Kathmandu Medical College, Kathmandu Nepal during August 2017 to July 2018. Perceived stress was assessed using Perceived Stress Scale-14 and perception of academic stress 18-item questionnaire was used to assess the academic factors of stress using self-administered technique. Result: The overall mean perceived stress score was $45.23 \pm 4.96,99.6 \%$ of participants were in the group of more stressed and overall mean score of perception of academic stress was $54.68 \pm 9.10$, and $56.3 \%$ of participants were in the group of academic stress. The correlation between perceived psychological stress and academic stress was 0.070 with $P$ value of 0.040 . Conclusion: Higher level of perceived stress and academic stress were reported by the students and there was weak significantly positive correlation between perceived psychological stress and academic stress.
\end{abstract}

Keywords: Academic factor, perceived stress, undergraduate students.

\section{*Correspondence:}

Ms Jyoti Badan Tuladhar

Kathmandu Medical College Teaching Hospital (Affiliated to Kathmandu University)

Email: jy.tuladhar@gmail.com

Submitted: April 2, 2021

Accepted: June 28, 2021

To cite: Tuladhar JB. Perceived psychological stress among undergraduate students: role of academic factors of a medical college of Kathmandu. JGMC Nepal. 2021;14(1):59-2. DOI: $10.3126 /$ jgmcn.v14i1.36233

Phone:+977-9847029240

\section{INTRODUCTION}

Stress is defined as "the relationship between the person and their surroundings, which is considered being physically or mentally demanding or as beyond his or her resources, putting their well-being at risk".1 Evidence has shown that the nursing students experience higher levels of stress than others because they have to deal with increased external stressors such as clinical responsibilities and course requirements. This can result in poor academic performance, and burnout. 2 It has also been reported that experience of specific academic hurdles makes them more sensitive to stress and anxiety than students in other fields.3 Likewise, the nursing students who engage in a wide range of clinical duties during their learning in clinical settings share similar stressors as professional nurses experience.4 Studies have shown that stress is prevalent among dental5and medical students as well.6

Academic related problems are the greater perceived stressor whereas stress can also significantly raise problem, causing a negative impact on the academic performance, emotional and 
physical difficulties as well as damage a student's feeling of self-worth.7,8 If the students are under more strain or stress, their learning and memory suffer, resulting in poor academic performance, low self-esteem and mental and physical problems.8

There are many studies done regarding perceived psychological stress in different countries, but similar literature is very less in Nepalese context. Hence, the study was aimed to assess the perceived psychological stress and perceived academic stress among undergraduate students.

\section{METHODS}

A cross-sectional, questionnaire- based survey was carried out among undergraduate students of Kathmandu Medical College, Nepal, from August 2017 to July 2018. Census method was used, so entire population was taken for the sample size after three constant follow-ups, which included 853 students, in which 548 students were from MBBS, 189 students from BDS and 116 students from Nursing, studying in first to fourth year.

Intern students were excluded as nursing students have no provision of internship. A Self-administered questionnaire was administered. The data collection tool comprised of three parts, part I consisted of socio-demographic related questions to collect personal details (age, sex, academic year, faculty, history of academic year failure, learning environment, etc.). Part II contained Perceived Stress Scale-14 (PSS-14) to measure the perceived psychological stress. The tool asked the respondents to indicate on Likert scale of 0 to 4, 0 indicating never, 1 indicating almost never, 2 indicating sometimes, 3 indicating fairly often and 4 indicating very often. ${ }^{9}$ The total score for PSS-14 ranged from 0 to 56 . A higher score indicates greater stress ${ }^{10}$ so 28 was taken as the operational cutoff value. Part III consisted of Perceive Academic Stress (PAS-18) to measure the perceived academic stress. The tool asked the respondents to rate on a Likert scale of 1 to 5 , with 1 indicating strongly disagree and 5 indicating strongly agree. The score for PAS-18 ranged from 18 to $90 .{ }^{11-14}$ The academic stress was categorized as high stress ( 54 and above) and low stress (53 and below) ${ }^{15}$ so 53 was taken as the operational cutoff value.

The ethical approval was taken from Institutional Review Committee of Kathmandu Medical College (Ref:02082017) and informed consent was taken from each respondent before collecting data. Data were coded on a data sheet, analyzed, edited and categorized on the basis of research objectives. Descriptive and inferential statistics were used to analyze the data by IBM SPSS version- 20 .

\section{RESULTS}

Table 1: Socio-demographic variables of the undergraduate students ( $\mathrm{n}=853$ )

\begin{tabular}{|c|c|c|}
\hline $\begin{array}{l}\text { Variables } \\
\text { Age (in years) }\end{array}$ & Frequency & Percentage \\
\hline Less than 20 & 147 & 17.2 \\
\hline More than 20 & 706 & 82.8 \\
\hline \multicolumn{3}{|c|}{ Mean age $\pm S D=20.95 \pm 1.54$ years } \\
\hline \multicolumn{3}{|l|}{ Sex } \\
\hline Male & 383 & 44.9 \\
\hline Female & 470 & 55.1 \\
\hline \multicolumn{3}{|l|}{ Marital Status } \\
\hline Married & 5 & 0.6 \\
\hline Unmarried & 848 & 99.4 \\
\hline \multicolumn{3}{|l|}{ Faculty } \\
\hline MBBS & 548 & 64.2 \\
\hline BDS & 189 & 22.2 \\
\hline Nursing & 116 & 13.6 \\
\hline \multicolumn{3}{|l|}{ Academic Year } \\
\hline MBBS First year & 115 & 13.5 \\
\hline MBBS Second year & 136 & 15.9 \\
\hline MBBS third year & 149 & 17.5 \\
\hline MBBS fourth year & 148 & 17.4 \\
\hline BDS First year & 40 & 4.7 \\
\hline BDS Second Year & 49 & 5.7 \\
\hline BDS Third year & 50 & 5.9 \\
\hline BDS Fourth year & 50 & 5.9 \\
\hline B.Sc.Nursing First year & 30 & 3.5 \\
\hline B.Sc.Nursing Second year & 30 & 3.5 \\
\hline B.Sc.Nursing Third year & 26 & 3 \\
\hline B.Sc.Nursing Fourth year & 30 & 3.5 \\
\hline \multicolumn{3}{|l|}{ Academic Failure } \\
\hline Yes & 227 & 26.6 \\
\hline No & 626 & 73.4 \\
\hline \multicolumn{3}{|c|}{ Satisfaction with the learning environment } \\
\hline Very Satisfying & 42 & 4.9 \\
\hline Satisfying & 470 & 55.1 \\
\hline Not very satisfying & 297 & 34.8 \\
\hline Not at all satisfying & 44 & 5.2 \\
\hline \multicolumn{3}{|c|}{ Satisfaction with home environment } \\
\hline Yes & 761 & 89.2 \\
\hline No & 92 & 10.8 \\
\hline
\end{tabular}

Among 853 students, 470 (55.1\%) were females and $383(44.9 \%)$ males. The mean age was $20.95 \pm 1.54$ years and most of the students (99.4\%) were unmarried. A total of $64.3 \%$ were from MBBS, $22.2 \%$ from BDS and $13.5 \%$ Nursing stream. Most of the students (73.4\%) had no history of academic failure. More than half of the students $(55.1 \%)$ had satisfying learning environment at college and most of the students (89.2\%) had a satisfying environment at home. (Table 1) Table 2 reveals that the maximum (99.6\%) students perceived more stress with the mean score of $45.23 \pm 4.96$. Table 3 reveals that more than half of the students (56.3\%) had perceived academic stress with the mean score of $54.68 \pm 9.10$. Table 4 shows that there is weak significantly positive corelation between Perceived Psychological Stress and Perceived Academic Stress $(\mathrm{P}=0.04)$. 
Table 2: Perceived stress among undergraduate students $(n=853)$

\begin{tabular}{lcc}
\hline Perceived Psychological Stress & Frequency & Percentage \\
Mean Perceived Stress Score $=45.23 \pm 4.96$ & & \\
High stressed (more than or equal to 28) & 850 & 99.6 \\
Low stressed (less than 28) & 3 & 0.4 \\
\hline
\end{tabular}

Table 3: Academic Stress among undergraduate students $(\mathrm{n}=853)$

\begin{tabular}{lcc}
\hline Perceived Academic Stress & Frequency & Percentage \\
Mean Perceived Academic Stress =54.68 \pm 9.10 & & \\
High Academic Stress (54 and above) & 480 & 56.3 \\
Low Academic Stress (less than or equal to 53) & 373 & 43.7 \\
\hline
\end{tabular}

Table 4: Correlation between Perceived Psychological Stress and Academic Stress ( $\mathrm{n}=853)$

\begin{tabular}{lcc}
\hline Variables & R & P value \\
Perceived Psychological Stress & 0.070 & $0.04^{*}$ \\
Perceived Academic Stress & & \\
\hline
\end{tabular}

*P value significant at $<0.05$

\section{DISCUSSION}

This study aimed to find out the perceived psychological stress and perceived academic stress among undergraduate students. More than half (55.1\%) students were females, in contradiction to the study done in India, in which more than two third (68.04\%) students were males. ${ }^{16}$ The mean age of the students was $20.95 \pm 1.54$ years which is similar to the study done in India. ${ }^{16}$

Students from the medical, dental and nursing field expected to learn and master a huge amount of knowledge, attitude and skills for which they have to work hard which puts them under a lot of stress. The current study revealed that the undergraduate students experienced high stress with the overall mean perceived stress score of $45.23 \pm 4.96$ which is contradictory form a study done in India, Saudi Arabia and Pakistan which reported the overall mean perceived stress score was $29.95( \pm 1.97)$, $23.46( \pm 7.77)$ and $30.84( \pm 7.01)^{6,16,17}$ respectively. The reason for this might be the use of different stress scoring scales like the PSS-10 scale. In the current study, the percentage experiencing high stress was 99.6\% which was similar to the study done in Surat, which reported that $96.8 \%$ of students experienced stress. ${ }^{18}$

In this study, more than half of the students (56.3\%) suffered from high academic stress with the overall mean perceived academic stress score of $54.68 \pm 9.10$ which is more than the cutoff point. This indicates that the students experience stress in different academic stress factors which is in contradiction to the study done in Malaysia which revealed that $80.88 \%$ of students were found to have a higher level of stress and another study done in Mainefhi, Eritrea also revealed $78.5 \%$ of students had academic stress ${ }^{15,19}$ which was higher than this study, it might be because of the satisfaction with learning environment and home environment.

In the current study, there was a weakly significant positive correlation between perceived psychological stress and perceived academic stress $(r=0.070 ; \mathrm{P}=0.04)$. This signifies that higher the academic stress of the students, the higher will be the perceived psychological stress. A study conducted in Pakistan revealed that there was a negative but insignificant correlation between perceived stress and academic performance $(\mathrm{r}=-0.099, \mathrm{P}>0.05)^{17}$ which is contradictory to this study.

\section{CONCLUSION}

A higher level of perceived stress and academic stress were reported by the students and there was a weak significant positive correlation between perceived psychological stress and perceived academic stress. Interventions to lower academic stress and to cope with the perceived psychological stress should be carried out so that the learning process of the students will be efficient.

\section{ACKNOWLEDGEMENT}

We would like to thank all the students included in the study for giving their valuable time. Also wish to thank Kathmandu Medical College Teaching Hospital for giving the opportunity for this study. We would like to give sincere gratitude to all the people who helped directly and indirectly in this study.

\section{REFERENCES}

1. Stress management in general practice. Occas Pap R Coll Gen Pract. 1993 Aug;(61):iv-vi, 1-42. PMID: 19790842.

2. Shultz Marie E. Factors related to stress in nursing students. HIM 1990-2015. 1183.2011. Available from: https://stars. library.ucf.edu/honorstheses1990-2015/1183. [Accessed $23^{\text {rd }}$ June 2019].

3. Bamuhair SS, Al Farhan AI, Althubaiti A, Agha S, Rahman S ur, Ibrahim NO. Sources of Stress and Coping Strategies among Undergraduate Medical Students Enrolled in a ProblemBased Learning Curriculum. J Biomed Educ.2015:e575139. DOI: $10.1155 / 2015 / 575139$

4. Liu M, Gu K, Wong TKS, Luo MZ, Chan MY. ScienceDirect Perceived stress among Macao nursing students in the clinical learning environment. Int J Nurs Sci. 2015;2(2):128- 


\section{DOI: 10.1016/j.ijnss.2015.04.013}

5. Paudel S, Subedi N, Shrestha A. Stress and its Relief among Undergraduate Dental Students in a Tertiary Health Care Centre in Eastern Nepal. Dentistry. 2013;3:157. DOI: 10.4172/2161-1122.1000157

6. Siddiqui AF, Al-Amri SA, Al-Katheri AA, Al-Hassani KHA. Perceived stress in Saudi undergraduate medical students. J Med Allied Sci. 2017;7(1):41-7. DOI:

$10.5455 /$ jmas. 252925

7. Gade S, Chari S, Gupta M. Perceived stress among medical students: To identify its sources and coping strategies. Arch Med Heal Sci. 2014;2(1):80-6.

8. Rafidah K, Azizah A, Norzaidi MD, Chong SC, Salwani MI, Noraini I. The Impact of Perceived Stress and Stress Factors on Academic Performance of Pre-Diploma Science Students: A Malaysian Study. 2009;2:13-26.

9. Cohen S. Perceived Stress Scale (PSS) | Measurement Instrument Database for the Social Science. Available from: http://www.midss.org/content/perceived-stress-scale-pss [Accessed 23 ${ }^{\text {rd }}$ June 2019].

10. Andreou E, Alexopoulos EC, Lionis C, Varvogli L, Gnardellis C, Chrousos GP, et al. Perceived Stress Scale: Reliability and validity study in Greece. Int J Environ Res Public Health. 2011;8(8):3287-98. DOI: 10.3390/ijerph8083287

11. Bedewy D, Gabriel A. Examining perceptions of academic stress and its sources among university students: The Perception of Academic Stress Scale. Heal Psychol Open. 2015;2(2):205510291559671. D O I : $10.1177 / 2055102915596714$ PMID: 28070363.

12. Jiang JM, Seng EK, Zimmerman ME, Sliwinski M, Kim M, Lipton RB. Evaluation of the Reliability, Validity, and Predictive Validity of the Subscales of the Perceived Stress
Scale in Older Adults. J Alzheimer's Dis. 2017;59(3):987-96. DOI: 10.3233/JAD-170289 PMID: 28671128.

13. Gazzaz ZJ, Baig M, Al Alhendi BSM, Al Suliman MMO, Al Alhendi AS, Al-Grad MSH, et al. Perceived stress, reasons for and sources of stress among medical students at Rabigh Medical College, King Abdulaziz University, Jeddah, Saudi Arabia. BMC Med Educ. 2018:18(1):1-9. DOI: 10.1186/ s12909-018-1133-2

14. Lee Teo L. Prevalence and Determinents of Perceived Stress among Undergraduate Students in a Malayaian University. JUMMEC. 2018: 21(1):1-5.

15. Chung COY, Ping DC, Zahari PS, Ravindran TS, Kannathasan K. The Association Between Self-esteem and Academic Stress Among Undergraduate Medical Students. International Journal of Biomedical and Clinical Sciences. 2020;5(2):6474.

16. Chowdhury R, Mukherjee A, Mitra K, Naskar S, Karmakar PR, Lahiri SK. Perceived Psychological Stress among Undergraduate Medical Students : Role of Academic Factors. 2017;55-7. DOI: 10.4103/0019-557X.200253 PMID: 28218165.

17. Shah M, Hasan S, Malik S, Sreeramareddy CT. Perceived stress, sources and severity of stress among medical undergraduates in a Pakistani medical school. BMC Med Educ. 2010:10(1). DOI: 10.1186/1472-6920-10-2

18. Solanky P, Desai B, Kavishwar A, Kantharia SL. Study of Psychological Stress among Undergraduate Medical Students of Government Medical College, Surat. Int J Med Sci Public Heal. 2012;1(2). DOI: 10.5455/ijmsph.2012.1.38-42

19. Yikealo D, Yemane B, Karvinen I, Yikealo D. The Level of Academic and Environmental Stress among College Students: A Case in the College of Education. Open J Soc Sci. 2018;6:40-57. DOI: 10.4236/jss.2018.611004 